\title{
Hypnotic modulation of resting state fMRI default mode and extrinsic network connectivity
}

\author{
A. Demertzi ${ }^{\dagger}$, A. Soddu ${ }^{\dagger}$, M.-E. Faymonville ${ }^{\star}$, M. A. Bahri ${ }^{\S}$, O. Gosseries ${ }^{\dagger}$, \\ A. Vanhaudenhuyse ${ }^{\dagger}$, C. Phillips ${ }^{\S}$,, P. Maquet ${ }^{\S}$, Q. Noirhomme ${ }^{\dagger}$, \\ A. Luxen ${ }^{\S}$ and S. Laureys ${ }^{\dagger}, *$ \\ ${ }^{\dagger}$ Coma Science Group, Cyclotron Research Centre and Neurology Department, University and University Hospital of \\ Liège, Liège, Belgium \\ * Pain Clinic, University Hospital of Liège, Liège, Belgium \\ $\S$ Cyclotron Research Centre, University of Liège, Liège, Belgium \\ - Department of Electrical Engineering and Computer Science, University of Liège, Liège, Belgium
}

\begin{abstract}
Resting state fMRI (functional magnetic resonance imaging) acquisitions are characterized by low-frequency spontaneous activity in a default mode network (encompassing medial brain areas and linked to self-related processes) and an anticorrelated "extrinsic" system (encompassing lateral frontoparietal areas and modulated via external sensory stimulation). In order to better determine the functional contribution of these networks to conscious awareness, we here sought to transiently modulate their relationship by means of hypnosis. We used independent component analysis (ICA) on resting state fMRI acquisitions during normal wakefulness, under hypnotic state, and during a control condition of autobiographical mental imagery. As compared to mental imagery, hypnosis-induced modulation of resting state fMRI networks resulted in a reduced "extrinsic" lateral frontoparietal cortical connectivity, possibly reflecting a decreased sensory awareness. The default mode network showed an increased connectivity in bilateral angular and middle frontal gyri, whereas its posterior midline and parahippocampal structures decreased their connectivity during hypnosis, supposedly related to an altered "self" awareness and posthypnotic amnesia. In our view, fMRI resting state studies of physiological (e.g., sleep or hypnosis), pharmacological (e.g., sedation or anesthesia), and pathological modulation (e.g., coma or related states) of "intrinsic" default mode and anticorrelated "extrinsic" sensory networks, and their interaction with other cerebral networks, will further improve our understanding of the neural correlates of subjective awareness.
\end{abstract}

Keywords: consciousness; hypnotic state; awareness; fMRI; default mode network; functional connectivity.

\footnotetext{
*Corresponding author.

Tel.: + 32-4-366-23-16; Fax: +32-4-366-29-46

E-mail: steven.laureys@ulg.ac.be
} 


\section{Introduction}

Spontaneous brain activity has recently received increasing interest in the neuroimaging community. However, the value of functional magnetic resonance imaging (fMRI) resting-state studies to a better understanding of brain-behavior relationships has been challenged (e.g., Boly et al., 2008). During task-negative conditions, several cerebral networks, characterized by low-frequency dynamic fluctuations, appear to play a potential functional role in sensory and higher cognitive functioning (Damoiseaux et al., 2006). Correlation analysis among these distinct networks has identified functional correlations between distinct somatosensory systems which in turn appear to anticorrelate with an "intrinsic system" or default network (Fox et al., 2005; Tian et al., 2007). More particularly, the "extrinsic" system, encompassing lateral frontoparietal areas, has been linked to processes of externally derived input via somatosensory (Boly et al., 2007; Bornhovd et al., 2002; Buchel et al., 2002), visual and auditory modalities (Fuhrmann et al., 2008; Rees, 2007). The default mode network encompasses midline brain areas and it has been associated with internally oriented cognitive processes, such as mind wandering or daydreaming (Mason et al., 2007; McKiernan et al., 2006), mental imagery (Knauff et al., 2003; Wang et al., 2008), inner speech (Morin and Michaud, 2007), and self-oriented thoughts (Goldberg et al., 2006; Lou et al., 2004). The functional significance of this anticorrelated pattern is not completely understood but there seems to be a link between cerebral function and its conscious behavioral counterpart under healthy situations (Vanhaudenhuyse et al., 2011) and during experimentally manipulated states of unconsciousness, such as anesthesia (Boveroux et al., 2010).

In order to better determine the functional contribution of these anticorrelated networks to consciousness, we sought to transiently modulate their relationship by means of hypnosis. Hypnosis is "a procedure during which a health professional or researcher suggests that a patient or subject experiences changes in sensations, perceptions, thoughts, or behavior" (The Executive Committee of the American Psychological Association-Division of Psychological Hypnosis, 1994) by inducing an altered state of consciousness with a distinct cerebral pattern (Maquet et al., 1999; Rainville et al., 2002). At the phenomenological level, hypnosis is characterized by increased degrees of private processes, such as absorption (i.e., the capacity to remain implicated in a mental state), dissociation (i.e., the mental separation from the environment), disorientation in time, space and person, diminished tendency to judge and censor, whereas it reduces spontaneous thoughts and gives the feeling of one's own response as automatic or extravolitional (Oakley and Halligan, 2009; Rainville and Price, 2003). The experimental manipulation of these basic dimensions of experience is thought to provide leverage to investigate not only the contents of consciousness but also the neural correlates of its background states (Chalmers, 2000).

We here used independent component analysis (ICA) on resting state fMRI acquisitions during normal wakefulness, under hypnotic state and during a control condition of autobiographical mental imagery. The ICA approach to study functional connectivity is a user-independent way to analyze complex signals as it does not require predefined regions of interest or the identification of a seed voxel location and is powerful to separate the neuronal from the global signal and other noise-related signal variations (Beckmann et al., 2005). Hence, the anticorrelations of the resting state cannot be explained as an artifact of the global signal regression, which underlies their biological basis (Fox et al., 2009).

We here hypothesized that, compared to autobiographical mental imagery, subjects under hypnotic state would report a phenomenology of an altered state of consciousness, showing increased "self" absorption, dissociated from decreased external sensory awareness. Recording of "resting 
state" fMRI networks under hypnosis was predicted to show an altered functional connectivity of both the default mode network and the anticorrelated "extrinsic" system.

\section{Methods}

\section{Subjects and procedure}

Twelve healthy subjects ( 4 women, 8 men; mean age 21 years, $\mathrm{SD} \pm 3$ ) with no previous neurological or psychiatric history participated in the study after giving written informed consent in accordance with the Ethics Committee of the Faculty of Medicine of the University of Liège. For their inclusion in the study, subjects needed to report an absorption and dissociation level $>6 / 10$ during a familiarization session with hypnosis which preceded the main experiment. During this session, detailed information about past pleasant life experiences, which the subject wanted to use during hypnotic induction, was obtained through a semi-structured interview as described elsewhere (Faymonville et al., 2003).

The hypnotic state was induced in the same way as in our patients during surgery (Faymonville et al., 1995, 1997, 1999) and as in our previous functional neuroimaging studies with healthy volunteers (Faymonville et al., 2003; Maquet et al., 1999; Vanhaudenhuyse et al., 2009a). The hypnotic instruction encompassed a 3-min induction procedure involving progressive eye fixation and muscle relaxation. Subjects were then invited to reexperience their pleasant autobiographical memories. As in clinical conditions, permissive and indirect suggestions were used to develop and deepen the hypnotic state. Subjects were continuously given cues for maintaining a hypnotic state. The exact words and details of the induction technique and specific suggestions and details during the course of the induction varied depending upon the experimenter's (M.E.F.) observation of subject behavior, and on her judgment of subjects' needs. During the experimental session, the experimenter remained silent.

\section{Data acquisition and analysis}

Three scanning sessions were performed: during normal wakefulness, under hypnotic state, and during a controlled condition of mental imagery of autobiographical memories (i.e., the same memories used in hypnotic session but here without the hypnotic induction). In order to exclude carry-over effects, the order of the sessions was randomized across subjects. In all subjects, resting state fMRI data were acquired on a 3T magnetic resonance scanner (Magnetom Allegra; Siemens Medical Solutions, Erlangen, Germany). Three hundred and fifty multislice $T_{2}{ }^{*}$-weighted fMRI images were obtained with a gradient echoplanar sequence using axial slice orientation (32 slices, FoV $=220 \times 220 \mathrm{~mm}^{2}$, voxel size $=3.4 \times 3.4 \times$ $3 \mathrm{~mm}^{3}, 30 \%$ interslice gap, matrix size $=64 \times$ $64 \times 32, \mathrm{TR}=2460 \mathrm{~ms}, \mathrm{TE}=40 \mathrm{~ms}, \mathrm{FA}=90^{\circ}$ ). Head movements were minimized using customized cushions. A T1 magnetization prepared rapid gradient echo sequence was also acquired in the same session for coregistration of subject's anatomy with functional data. The most comfortable supine position attainable was sought to avoid painful stimulation related to position. During data acquisition, subjects wore earplugs and headphones through which they were receiving the instructions for the hypnotic induction. After each session, subjects were asked to rate on a 0 (not at all) to 10 (fully) scale their subjective experiences concerning the level of arousal, absorption, dissociation, and external thoughts.

fMRI data were preprocessed and analyzed with "Brain Voyager" software package (Brain Innovation, Maastricht, The Netherlands). Preprocessing of functional scans included 3D motion correction, linear trend removal, slice scan time correction and filtering out low frequencies of up to $0.005 \mathrm{~Hz}$. The data were spatially smoothed with a Gaussian filter of full width at 
half maximum value of $6 \mathrm{~mm}$. The first three fMRI volumes were discarded to allow for signal equilibration. In two subjects, 197 scans were kept in the analysis due to increased motion across time (i.e., $>6 \mathrm{~mm}$ ). The functional images from each participant were each aligned to the participant's own anatomical scan and warped into the standard anatomical space of Talairach and Tournoux, 1988 by individually defining bounding boxes for the entire brain, using anterior commisure (AC) and posterior commisure (PC) as anchor points for the transformation. ICA, as implemented in "Brain Voyager" (Formisano et al., 2004), was performed using 30 components (Ylipaavalniemi and Vigario, 2008). Then selforganizing ICA (Esposito et al., 2005) permitted a spatial similarity test on single subjects' independent components and an averaged template obtained in seven independent controls (mean age $=48$ years, $\mathrm{SD} \pm 13$, range: $25-65,3$ females; 300 functional scans acquired on a 3T MR scanner, Trio Tim, Siemens, Germany; gradient echoplanar sequence with axial slice orientation: 32 slices; voxel size: $3.0 \times 3.0 \times 3.75 \mathrm{~mm}^{3}$; matrix size: $64 \times 64 \times 32$; repetition time: $2,000 \mathrm{~ms}$, echo time $1 / 4$ $30 \mathrm{~ms}$, flip angle: $78^{\circ}$; field of view: $192 \mathrm{~mm}$ ).

At a first-level analysis, the component of interest ( $z$-map) was transformed into a statistical parametric map (SPM) for each individual subject: the time courses of all components but that of interest (i.e., which contained the $z$ values of the two systems) were used to regress out the initial BOLD signal; the saved residuals represented the BOLD activity of the default mode and the "extrinsic" system. Then by using the time course of the component of interest as a predictor of this residual BOLD activity, the $t$-maps were obtained. At a second-level analysis, the beta values extracted from the previous step were entered in repeated-measures multiple subjects general linear models (random effects) with three levels (normal wakefulness, hypnotic state, mental imagery). One-sample ANOVAs (FDR corrected $p<0.05)$ were ordered to calculate the mean effects of each level. The contrast between hypnotic state versus mental imagery was ordered. Statistical parametric maps resulting from the voxel wise analysis were considered significant for statistical values that survived a cluster-based correction for multiple comparisons as implemented in Brain Voyager (Goebel et al., 2006) using the "cluster-level statistical threshold estimator" plug-in. This approach to correction for multiple comparisons is based on a $3 \mathrm{D}$ extension of the randomization procedure described by Forman and colleagues (Forman et al., 1995). First, voxel-level threshold was set at $t=2.2$ ( $p=0.05$, uncorrected). Thresholded maps were then submitted to a region of interest (ROI) brain-based correction criterion (masks for the default mode and "extrinsic" systems) that was based on the estimate of the map's spatial smoothness and on an iterative procedure (Monte Carlo simulation) for estimating cluster-level false-positive rates. After 1000 iterations, the minimum cluster size threshold that yielded a clusterlevel false positive rate of $5 \%$ was applied to the statistical maps. After each session, subjective reports were collected as regards the level of arousal, absorption, dissociation and intensity of external thoughts on a 10-point scale ( 0 : not at all, 10: totally). Wilcoxon's signed-rank tests (SPSS v. 16) were preformed to test the differences in scores within each variable across the three conditions per subject. Results were considered significant at a $\mathrm{p}<0.05$ (two-tailed).

\section{Results}

Participants reported similar arousal scores during normal wakefulness $(6.4 \pm 2.0$ mean and SD; range 2-10), mental imagery $6.1 \pm 1.8$ (range $3-8)$, and hypnotic state $(5.3 \pm 2.3)$. Dissociation and absorption scores were higher in hypnotic state as compared to mental imagery and normal wakefulness. Self-reported intensity scores of external thoughts were lower in hypnotic state, as compared to mental imagery and normal wakefulness (Fig. 1). 


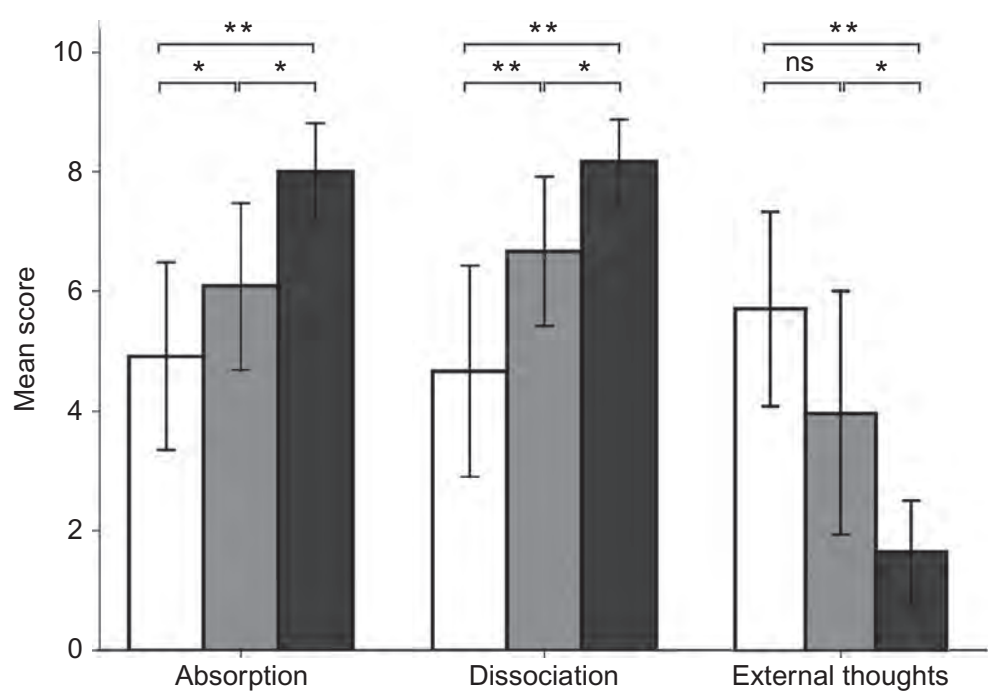

Fig. 1. Absorption, dissociation, and external awareness scores in normal wakefulness (white), autobiographical mental imagery (light gray), and hypnotic state (dark gray) (mean values with $95 \%$ confidence intervals; $* * p<0.01 ; * p<0.05$ ).

In normal wakefulness, the identified default mode network encompassed posterior cingulate and adjacent precuneal cortices, anterior cingulate and adjacent medial prefrontal cortices, bilateral angular, middle and inferior temporal, and parahippocampal gyri. The anticorrelated "extrinsic" system encompassed bilateral inferior frontal and supramarginal gyri (Table 1). In autobiographical mental imagery, the identified default mode and anticorrelated "extrinsic" networks encompassed similar areas as described above albeit less widespread (Table 2). In hypnotic state, a further decrease in default mode and "extrinsic" network connectivity extent and intensity was observed, as illustrated graphically in Fig. 2.

The comparison between hypnosis and mental imagery showed an increased connectivity in part of the default network encompassing the middle frontal and bilateral angular gyri whereas the restrosplenial/posterior cingulate and bilateral parahippocampal areas showed a decreased connectivity. The "extrinsic" network did not show any increased connectivity but we identified a decreased connectivity in the right supramarginal and left superior temporal areas in hypnosis as compared to mental imagery (Table 3; Fig. 3).

\section{Discussion}

Resting state fMRI acquisitions are characterized by low-frequency spontaneous activity in a default mode network (i.e., relatively decoupled from external input, encompassing medial brain areas and linked to self-related processes; Gusnard and Raichle, 2001) and an anticorrelated "extrinsic" or externally oriented network (i.e., modulated via external sensory stimulation encompassing lateral parietal areas; Damoiseaux et al., 2006; Golland et al., 2007; Raichle et al., 2001). We here aimed to determine how these two networks are influenced by a transient altered conscious state, such as hypnosis. In normal wakefulness, we first identified both networks in accordance to prior studies (Damoiseaux et al., 2006; Fox et al., 2005; Golland et al., 2007; Tian et al., 2007). The relationship between these two 
Table 1. Peak voxels of the default mode network and anticorrelated extrinsic system identified in normal wakefulness

\begin{tabular}{|c|c|c|c|c|c|c|c|}
\hline \multicolumn{2}{|c|}{ Common names (Brodmann area) } & $\begin{array}{l}\text { Cluster size } \\
\text { (number of voxels) }\end{array}$ & $x$ & $y$ & $z$ & $t$ & $p$ \\
\hline \multicolumn{8}{|c|}{ Default mode network } \\
\hline & Posterior cingulate/precuneus $(23,31,7)$ & 68,050 & -1 & -59 & 24 & 25.19 & $<0.001$ \\
\hline & Medial prefrontal cortex/anterior cingulate $(24,32,10)$ & 47,407 & -1 & 40 & 12 & 14.89 & $<0.001$ \\
\hline $\mathrm{R}$ & Angular gyrus (39) & 7287 & 47 & -59 & 18 & 11.31 & $<0.001$ \\
\hline $\mathrm{L}$ & Angular gyrus (39) & 5609 & -43 & -59 & 21 & 8.20 & $<0.001$ \\
\hline $\mathrm{R}$ & Middle temporal gyrus (21) & 3827 & 62 & -8 & -15 & 6.91 & $<0.001$ \\
\hline $\mathrm{L}$ & Middle temporal gyrus (21) & 4594 & -55 & -17 & -12 & 9.66 & $<0.001$ \\
\hline $\mathrm{R}$ & Inferior temporal gyrus (38) & 521 & 41 & 22 & -24 & 5.49 & $<0.001$ \\
\hline $\mathrm{L}$ & Inferior temporal gyrus (38) & 255 & -43 & 22 & -21 & 5.20 & $<0.001$ \\
\hline \multirow[t]{5}{*}{$\mathrm{L}$} & Postcentral gyrus (2) & 313 & -13 & -29 & 69 & 5.97 & $<0.001$ \\
\hline & Medial occipitotemporal gyrus (17) & 278 & -7 & -89 & 6 & 4.30 & 0.001 \\
\hline & Thalamus & 421 & 2 & -17 & 15 & 4.91 & $<0.001$ \\
\hline & Brainstem & 510 & -1 & -23 & -24 & 7.52 & $<0.001$ \\
\hline & Cerebellar tonsils & 252 & 5 & -53 & -33 & 4.95 & $<0.001$ \\
\hline \multicolumn{8}{|c|}{ Extrinsic system } \\
\hline $\mathrm{R}$ & Inferior frontal gyrus (45) & 10,403 & 41 & 1 & 15 & -7.32 & $<0.001$ \\
\hline $\mathrm{R}$ & Inferior frontal gyrus (47) & 376 & 47 & 31 & 0 & -5.10 & $<0.001$ \\
\hline $\mathrm{L}$ & Inferior frontal gyrus (47) & 12,612 & -49 & 19 & -3 & -7.98 & $<0.001$ \\
\hline $\mathrm{R}$ & Supermarginal gyrus (40) & 3971 & 53 & -32 & 24 & -7.02 & $<0.001$ \\
\hline $\mathrm{L}$ & Supermarginal gyrus (40) & 2923 & -67 & -29 & 15 & -5.79 & $<0.001$ \\
\hline $\mathrm{L}$ & Superior frontal gyrus (9) & 1416 & -40 & 37 & 27 & -5.58 & $<0.001$ \\
\hline $\mathrm{L}$ & Medial frontal gyrus (32) & 4130 & -4 & 7 & 45 & -7.67 & $<0.001$ \\
\hline $\mathrm{L}$ & Precentral gyrus (6) & 615 & -46 & -2 & 45 & -5.05 & $<0.001$ \\
\hline \multirow[t]{2}{*}{$\mathrm{L}$} & Inferior occipital gyrus (19) & 469 & -43 & -53 & 0 & -5.21 & $<0.001$ \\
\hline & Anterior cingulate gyrus (24) & 437 & 17 & -20 & 42 & -5.44 & $<0.001$ \\
\hline
\end{tabular}

Stereotaxic coordinates are in normalized Talairach space, $p$ values are FDR corrected for multiple comparisons at the whole brain level.

networks at conscious resting state has been previously characterized as competing, where one system can disturb or even interrupt the other (Boly et al., 2008; Fox et al., 2005; Golland et al., 2007; Tian et al., 2007) with a consequence on the way we perceive the external world. For example, this ongoing resting activity has been shown to mediate sensory awareness in the sense that increased activity in the "extrinsic" frontoparietal network seemed to facilitate the conscious perception of low-intensity somatosensory stimuli, whereas unperceived intensitymatched stimuli were preceded by increased activity in the default mode network (Boly et al., 2007). Previous studies have also shown that increasing attentional demands in cognitive tasks lead to decreased activity in the default mode network (McKiernan et al., 2003) and lapses in attention were shown to correlate with reduced prestimulus activity in the anterior cingulate and right prefrontal regions, areas involved in controlling attention (Weissman et al., 2006). We recently showed that this opposed functionality of the default mode and anticorrelated "extrinsic" system has a cognitive behavioral counterpart. Explicit subjective reports for increased intensity of "internal" awareness (i.e., self-related stimulus-independent processes) were related to increased connectivity in the default network, whereas increased "external" awareness scores (i.e., perception of the environment) was associated with increased connectivity in the 
Table 2. Peak voxels of the default mode network and anticorrelated extrinsic system identified in mental imagery (A) and hypnotic state (B)

\begin{tabular}{|c|c|c|c|c|c|c|c|}
\hline $\begin{array}{l}\text { Common names } \\
\text { (Brodmann area) }\end{array}$ & & $\begin{array}{l}\text { Cluster size } \\
\text { (number of voxels) }\end{array}$ & $x$ & $y$ & $z$ & $t$ & $p$ \\
\hline \multicolumn{8}{|l|}{ A. Mental imagery } \\
\hline \multicolumn{8}{|c|}{ Default mode network } \\
\hline & $\begin{array}{l}\text { Posterior cingulate/precuneus }(23, \\
30,7)\end{array}$ & 31,502 & -7 & -53 & 12 & 19.79 & $<0.001$ \\
\hline $\mathrm{R}$ & Angular gyrus (39) & 1908 & 38 & -62 & 21 & 6.08 & $<0.001$ \\
\hline $\mathrm{L}$ & Angular gyrus (39) & 2068 & -40 & -62 & 27 & 6.8 & $<0.001$ \\
\hline $\mathrm{R}$ & Parahippocampal gyrus (35) & 2874 & 26 & -26 & -15 & 10.08 & $<0.001$ \\
\hline $\mathrm{R}$ & Middle frontal gyrus (8) & 923 & 23 & 19 & 42 & 6.46 & $<0.001$ \\
\hline $\mathrm{L}$ & Middle frontal gyrus (8) & 823 & -22 & 19 & 36 & 6.67 & $<0.001$ \\
\hline $\mathrm{L}$ & Superior temporal gyrus (38) & 309 & -34 & 22 & -24 & 5.41 & $<0.001$ \\
\hline $\mathrm{R}$ & Inferior frontal gyrus (44) & 4167 & 47 & 7 & 6 & -8.05 & $<0.001$ \\
\hline $\mathrm{L}$ & Inferior frontal gyrus (6) & 3063 & -49 & 4 & 21 & -7.15 & $<0.001$ \\
\hline $\mathrm{L}$ & Inferior frontal gyrus (44) & 1461 & -43 & 34 & 18 & -5.48 & $<0.001$ \\
\hline $\mathrm{R}$ & Supermarginal gyrus (40) & 5863 & 53 & -32 & 36 & -7.49 & $<0.001$ \\
\hline $\mathrm{L}$ & Supermarginal gyrus (40) & 4715 & -61 & -32 & 33 & -8.17 & $<0.001$ \\
\hline $\mathrm{R}$ & Middle occipital gyrus (17) & 337 & 29 & -80 & 9 & -5.61 & $<0.001$ \\
\hline \multicolumn{8}{|l|}{ B. Hypnotic state } \\
\hline \multicolumn{8}{|c|}{ Default mode network } \\
\hline & Posterior cingulate/precuneus (31) & 14,718 & -4 & -56 & 30 & 17.95 & $<0.001$ \\
\hline & $\begin{array}{l}\text { Anterior cingulate/mesiofrontal } \\
\text { (32) }\end{array}$ & 8272 & -4 & 28 & -9 & 7.29 & $<0.001$ \\
\hline
\end{tabular}

Stereotaxic coordinates are in normalized Talairach space, $p$ values are FDR corrected for multiple comparisons at the whole brain level.

"extrinsic" system (Vanhaudenhuyse et al., 2011), confirming the functional significance underlying the activity of both resting networks to conscious experience in health and disease (e.g., Laureys et al., 2007; Qin et al., 2010).

The selection of a control condition for hypnotic state remains challenging as, a priori, no cerebral state is close to hypnotic state. Thus, results from studies with hypnosis need to be interpreted based on the chosen control condition because the generation of different types of mental images will be associated with different cerebral activation patterns (e.g., Gardini et al., 2005; Ishai et al., 2000). We here chose to study hypnotic state as we use it in the clinical setting and during surgery (Faymonville et al., 1997, 


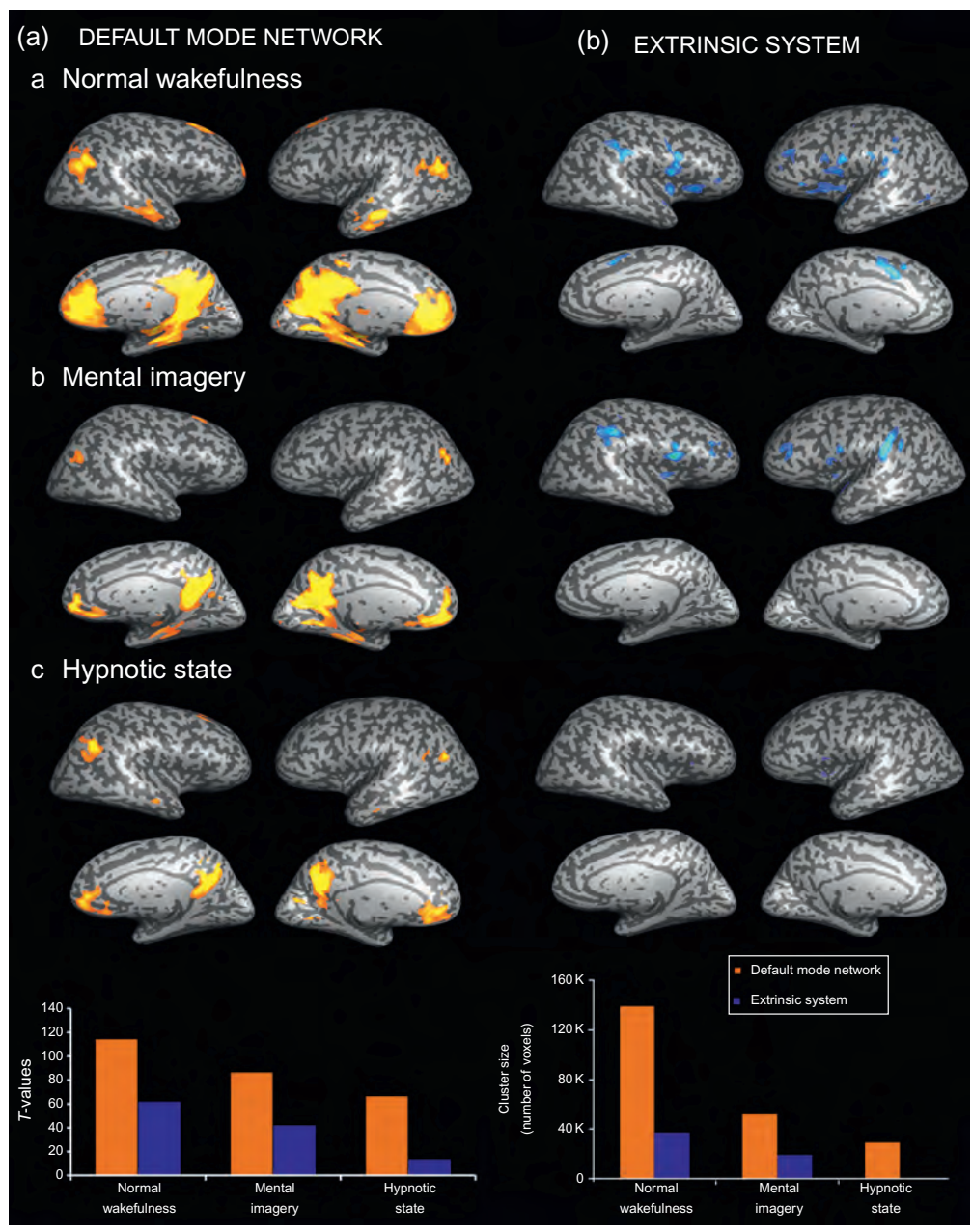

Fig. 2. The default mode network (a) and its anticorrelated "extrinsic" system (b) under normal wakefulness, mental imagery, and hypnotic state. Results are thresholded at whole brain false discovery rate corrected $p<0.05$. The graphs illustrate the global connectivity strength (left; summed $T$ values of all identified clusters in the random effect analysis) and extend (right; total number of voxels of all identified clusters) in both networks during the three conditions.

2000), asking subjects to revive pleasant autobiographical memories. Hence, our control condition employed mental imagery of pleasant autobiographical memories without induction of hypnosis because it is characterized by a polymodal content (motor, visual, and contextual) of episodic nature (Conway and Pleydell-Pearce, 2000).

We here observed that, in comparison to autobiographical mental imagery, under hypnosis the "extrinsic" system exhibited reduced functional connectivity, whereas the default network showed reduced connectivity in its posterior midline and parahippocampal structures but increased connectivity in its lateral parietal and middle frontal areas. The hypnosis-related increases in cerebral connectivity is in line with previous activation studies showing enhanced functional connectivity of anterior midline structures during hypnotic 
Table 3. Peak voxels of areas showing increased and decreased connectivity in (A) the default mode network and (B) extrinsic system in hypnotic state as compared to mental imagery

\begin{tabular}{|c|c|c|c|c|c|c|c|}
\hline $\begin{array}{l}\text { Common names } \\
\text { (Brodmann area) }\end{array}$ & & $\begin{array}{l}\text { Cluster size } \\
\text { (number of } \\
\text { voxels) }\end{array}$ & $x$ & $y$ & $z$ & $t$ & $p$ \\
\hline \multicolumn{8}{|c|}{$\begin{array}{l}\text { A. Default mode network } \\
\text { Increases in connectivity }\end{array}$} \\
\hline $\mathrm{R}$ & Medial prefrontal (10) & 2417 & 8 & 62 & 18 & 3.53 & 0.005 \\
\hline $\mathrm{L}$ & Angular gyrus (39) & 997 & -58 & -52 & 18 & 3.21 & 0.008 \\
\hline $\mathrm{R}$ & Angular gyrus (39) & 775 & 51 & -59 & 33 & 3.03 & 0.011 \\
\hline \multicolumn{8}{|c|}{ Decreases in connectivity } \\
\hline $\mathrm{L}$ & $\begin{array}{l}\text { Parahippocampal gyrus (35)/ Posterior } \\
\text { cingulate (30) }\end{array}$ & 19,088 & -25 & -23 & -18 & -6.33 & $<0.0001$ \\
\hline \multicolumn{8}{|c|}{$\begin{array}{l}\text { B. Extrinsic system } \\
\text { Increases in connectivity } \\
\text { - }\end{array}$} \\
\hline \multicolumn{8}{|c|}{ Decreases in connectivity } \\
\hline $\mathrm{R}$ & Supermarginal gyrus (40) & 385 & 47 & -39 & 27 & -2.98 & 0.013 \\
\hline $\mathrm{L}$ & Superior temporal gyrus (22) & 936 & -68 & -32 & 18 & -4.64 & 0.001 \\
\hline
\end{tabular}

Stereotaxic coordinates are in normalized Talairach space, $p$ values are cluster level corrected.

analgesia (Faymonville et al., 2003). Frontal increases in regional cerebral blood flow have also previously been demonstrated by positron emission tomography (PET) in the hypnotic state (e.g., Faymonville et al., 2000; Rainville et al., 1999) However, a recent fMRI study showed a hypnosis-related reduction in default mode connectivity in the middle frontal areas (McGeown et al., 2009). These divergent findings may be explained by the distinct suggestion instructions used to induce hypnosis and the different experimental fMRI designs utilized. In our study, we acquired continuous eyes-closed resting state data during each condition where pleasant autobiographical memories were performed during both hypnosis and the control mental imagery task. McGeown et al. (2009) employed a block design comparing an eyes-open visual perceptual task with and without hypnosis. It could also be that the observed persisting activity in the anterior midline part of the default network in our study is due to the chosen less challenging experimental conditions (Greicius and Menon, 2004).
The observed reduction in connectivity of the posterior midline parts of the default mode network during hypnosis might reflect a decreased degree of continuous information gathering from the external world with its relation to oneself (Gusnard and Raichle, 2001). These posterior retrosplenial, cingulate, and precuneal areas of the default network have been previously associated with various cognitive functions, such as visuospatial orientation, episodic memory retrieval, and self-processing (e.g., self-relevance, social cognition, visuospatial perspective taking, and agency; Cavanna and Trimble, 2006) and support functions concerning both orientation within, and interpretation of, the environment (Vogt and Laureys, 2005). The special contribution of the precuneus to consciousness is supported by evidence of its dysfunction in profound unconscious states, such as deep sleep (Horovitz et al., 2009), pharmacological coma (Boveroux et al., in press), and pathological coma and vegetative states (Laureys et al., 1999; Vanhaudenhuyse et al., 2009b) suggesting that it is a critical node in the neural network subserving conscious 


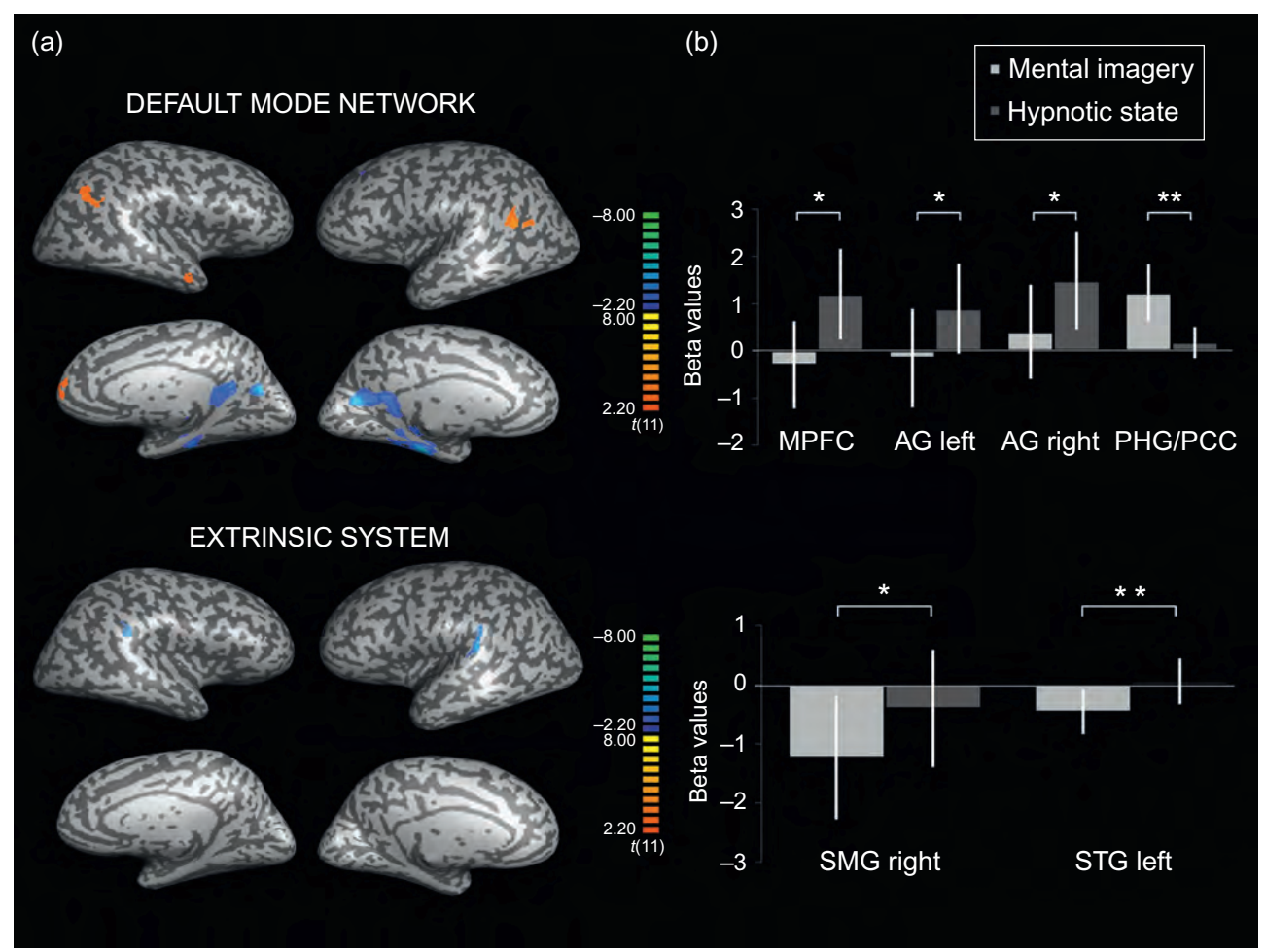

Fig. 3. Increased (in red) and decreased (in blue) functional connectivity in the default mode network and its anticorrelated "extrinsic" system. Results are thresholded at cluster level corrected $p<0.05$. The graph illustrates the effect size in the medial prefrontral cortex (MPFC), bilateral angular gyri (AG), and parahippocampal gyrus/posterior cingulate cortex (PHG/PCC) for the default mode network and in the temporoparietal cortices (supramarginal gyrus-SMG and superior temporal gyrus-STG) for the extrinsic system (mean beta values and 95\% confidence intervals).

experience (Baars et al., 2003). Our results on decreased connectivity of retrosplenial and posterior cingulate cortices extend previous PET studies demonstrating prominent reductions in regional blood flow and metabolism in these posterior midline structures during the hypnotic state (e.g., for review, see Faymonville et al., 2006).

The generation of autobiographical episodic mental images, as evoked in the present study in both normal and hypnotic conditions, is known to involve posterior cingulate, precuneal, and parahippocampal areas (Gardini et al., 2006). The reported reduced connectivity in the latter can be related to posthypnotic amnesia (Barber, 2000), thought to involve a disruption of retrieval processes similar to the functional amnesias observed in clinical dissociative disorders (Kihlstrom, 1997).

The decreased functional connectivity observed in the lateral frontoparietal "extrinsic" system, along with the subjective reports of diminished external awareness, might reflect a blockage of the sensory systems to receive sensory stimuli as a result of hypnotic suggestion which was shown to induce (Derbyshire et al., 2004) or alter somatosensory perceptions (Cojan et al., 2009). Increasing evidence points to the critical role of lateral associative frontoparietal cortical network in the emergence of conscious sensory perception 
(e.g., Boveroux et al., 2008; Laureys, 2005). The observed hypnosis-induced decreased frontoparietal connectivity could elucidate the clinical finding that patients undergoing surgery during hypnosedation (e.g., Faymonville et al., 1997) show modified phenomenological sensory awareness of their aversive encounters (e.g., see Kupers et al., 2005).

Our results are also in line with a previous suggested framework (Soddu et al., 2009), where it was hypothesized that a hypofunctional "extrinsic" system and a preserved default network activity would account for the participants' subjective experience of disengagement from their external environment leading to a "self-centered absorption" state, translated into a reduced sensory responsivity (i.e., limitation of sensory input or reduced motor output). Indeed, according to the behavioral data, participants reported a higher degree of absorption and dissociation from their surroundings during hypnosis as compared to mental imagery and normal wakefulness. Past phenomenological analysis of reports from subjects in hypnotic state suggests a diminished tendency to judge and monitor, a disorientation in time, space, and person and the experience of one's own response as automatic (Rainville and Price, 2003). Such increased absorption and dissociation levels during hypnotic state account for its antinociceptive effects during various surgical procedures, where hypnosis in combination with local anesthesia and minimal conscious sedation (i.e., "hypnosedation") is used to reduce pain, anxiety, intraoperative use of anxiolytic and analgesic drugs as well as faster recovery of the patient (Faymonville et al., 1998, 2006).

In conclusion, hypnosis-induced modulation of resting state fMRI networks, as compared to mental imagery, seems to result in a reduced "extrinsic" lateral frontoparietal cortical connectivity, possibly reflecting a decreased sensory awareness. The default mode network showed an increased connectivity in bilateral angular and middle frontal gyri whereas its parahippocampal and posterior midline structures decreased their connectivity during hypnosis, putatively related to an altered "self"-awareness and posthypnotic amnesia. In our view, fMRI "resting state" studies of physiological (e.g., sleep or hypnosis), pharmacological (e.g., sedation or anesthesia), and pathological modulation (e.g., coma or related states) of "intrinsic" default mode and anticorrelated "extrinsic" sensory networks and their interaction with other cerebral networks will further improve our understanding of the neural correlates of subjective awareness.

\section{Acknowledgments}

This research was funded by the Belgian National Funds for Scientific Research (FNRS), the European Commission (DISCOS, Marie-Curie Actions), the James McDonnell Foundation, the Mind Science Foundation, the French Speaking Community Concerted Research Action (ARC06/11-340), the Fondation Médicale Reine Elisabeth and the University of Liège.

\section{References}

Baars, B. J., Ramsoy, T. Z., \& Laureys, S. (2003). Brain, conscious experience and the observing self. Trends in Neurosciences, 26(12), 671-675.

Barber, T. X. (2000). A deeper understanding of hypnosis: Its secrets, its nature, its essence. The American Journal of Clinical Hypnosis, 42(3-4), 208-272.

Beckmann, C. F., DeLuca, M., Devlin, J. T., \& Smith, S. M. (2005). Investigations into resting-state connectivity using independent component analysis. Philosophical Transactions of the Royal Society of London. Series B, Biological Sciences, 360(1457), 1001-1013.

Boly, M., Balteau, E., Schnakers, C., Degueldre, C., Moonen, G., Luxen, A., et al. (2007). Baseline brain activity fluctuations predict somatosensory perception in humans. Proceedings of the National Academy of Sciences of the United States of America, 104(29), 12187-12192.

Boly, M., Phillips, C., Tshibanda, L., Vanhaudenhuyse, A., Schabus, M., Dang-Vu, T. T., et al. (2008). Intrinsic brain activity in altered states of consciousness: How conscious is the default mode of brain function? Annals of the New York Academy of Sciences, 1129, 119-129. 
Bornhovd, K., Quante, M., Glauche, V., Bromm, B., Weiller, C., \& Buchel, C. (2002). Painful stimuli evoke different stimulus-response functions in the amygdala, prefrontal, insula and somatosensory cortex: A single-trial fMRI study. Brain, 125(6), 1326-1336.

Boveroux, P., Bonhomme, V., Boly, M., Vanhaudenhuyse, A., Maquet, P., \& Laureys, S. (2008). Brain function in physiologically, pharmacologically, and pathologically altered states of consciousness. International Anesthesiology Clinics, 46(3), 131-146.

Boveroux, P., Vanhaudenhuyse, A., Bruno, M. A., Noirhomme, Q., Lauwick, S., Luxen, A., et al. (2010). Breakdown of within- and between-network resting state functional magnetic resonance imaging connectivity during propofol-induced loss of consciousness. Anesthesiology, 113(5), 1038-1053.

Buchel, C., Bornhovd, K., Quante, M., Glauche, V., Bromm, B., \& Weiller, C. (2002). Dissociable neural responses related to pain intensity, stimulus intensity, and stimulus awareness within the anterior cingulate cortex: A parametric single-trial laser functional magnetic resonance imaging study. The Journal of Neuroscience, 22(3), 970-976.

Cavanna, A. E., \& Trimble, M. R. (2006). The precuneus: A review of its functional anatomy and behavioural correlates. Brain, 129(3), 564-583.

Chalmers, D. J. (2000). What is a neural correlate of consiousness? In T. Metzinger (Ed.), Neural correlates of cosnciousness. Empirical and conceptual questions (pp. 17-39). Cambridge: MIT Press.

Cojan, Y., Waber, L., Schwartz, S., Rossier, L., Forster, A., \& Vuilleumier, P. (2009). The brain under self-control: Modulation of inhibitory and monitoring cortical networks during hypnotic paralysis. Neuron, 62(6), 862-875.

Conway, M. A., \& Pleydell-Pearce, C. W. (2000). The construction of autobiographical memories in the self-memory system. Psychological Review, 107(2), 261-288.

Damoiseaux, J. S., Rombouts, S. A., Barkhof, F., Scheltens, P., Stam, C. J., Smith, S. M., et al. (2006). Consistent restingstate networks across healthy subjects. Proceedings of the National Academy of Sciences of the United States of America, 103(37), 13848-13853.

Derbyshire, S. W., Whalley, M. G., Stenger, V. A., \& Oakley, D. A. (2004). Cerebral activation during hypnotically induced and imagined pain. NeuroImage, 23(1), 392-401.

Esposito, F., Scarabino, T., Hyvarinen, A., Himberg, J., Formisano, E., Comani, S., et al. (2005). Independent component analysis of fMRI group studies by self-organizing clustering. NeuroImage, 25(1), 193-205.

Faymonville, M. E., Boly, M., \& Laureys, S. (2006). Functional neuroanatomy of the hypnotic state. Journal of Physiology, Paris, 99(4-6), 463-469.
Faymonville, M. E., Defechereux, T., Joris, J., Adant, J. P., Hamoir, E., \& Meurisse, M. (1998). Hypnosis and its application in surgery. Revue Médicale de Liège, 53(7), 414-418.

Faymonville, M. E., Fissette, J., Mambourg, P. H., Roediger, L., Joris, J., \& Lamy, M. (1995). Hypnosis as adjunct therapy in conscious sedation for plastic surgery. Regional Anesthesia, 20(2), 145-151.

Faymonville, M. E., Laureys, S., Degueldre, C., DelFiore, G., Luxen, A., Franck, G., et al. (2000). Neural mechanisms of antinociceptive effects of hypnosis. Anesthesiology, 92(5), 1257-1267.

Faymonville, M. E., Mambourg, P. H., Joris, J., Vrijens, B., Fissette, J., Albert, A., et al. (1997). Psychological approaches during conscious sedation. Hypnosis versus stress reducing strategies: A prospective randomized study. Pain, 73(3), 361-367.

Faymonville, M. E., Meurisse, M., \& Fissette, J. (1999). Hypnosedation: A valuable alternative to traditional anaesthetic techniques. Acta Chirurgica Belgica, 99(4), 141-146.

Faymonville, M. E., Roediger, L., Del Fiore, G., Delgueldre, C., Phillips, C., Lamy, M., et al. (2003). Increased cerebral functional connectivity underlying the antinociceptive effects of hypnosis. Cognitive Brain Research, 17(2), 255-262.

Forman, S. D., Cohen, J. D., Fitzgerald, M., Eddy, W. F., Mintun, M. A., \& Noll, D. C. (1995). Improved assessment of significant activation in functional magnetic resonance imaging (fMRI): Use of a cluster-size threshold. Magnetic Resonance in Medicine, 33(5), 636-647.

Formisano, E., Esposito, F., Di Salle, F., \& Goebel, R. (2004). Cortex-based independent component analysis of fMRI time series. Magnetic Resonance Imaging, 22(10), 1493-1504.

Fox, M. D., Snyder, A. Z., Vincent, J. L., Corbetta, M., Van Essen, D. C., \& Raichle, M. E. (2005). The human brain is intrinsically organized into dynamic, anticorrelated functional networks. Proceedings of the National Academy of Sciences of the United States of America, 102(27), 9673-9678.

Fox, M. D., Zhang, D., Snyder, A. Z., \& Raichle, M. E. (2009). The global signal and observed anticorrelated resting state brain networks. Journal of Neurophysiology, 101(6), 3270-3283.

Fuhrmann, A. G., Hein, G., Tsai, N., Naumer, M. J., \& Knight, R. T. (2008). Temporal characteristics of audiovisual information processing. The Journal of Neuroscience, 28 (no 20), 5344-5349.

Gardini, S., Cornoldi, C., De Beni, R., \& Venneri, A. (2006). Left mediotemporal structures mediate the retrieval of episodic autobiographical mental images. NeuroImage, 30(2), 645-655.

Gardini, S., De Beni, R., Cornoldi, C., Bromiley, A., \& Venneri, A. (2005). Different neuronal pathways support 
the generation of general and specific mental images. NeuroImage, 27(3), 544-552.

Goebel, R., Esposito, F., \& Formisano, E. (2006). Analysis of functional image analysis contest (FIAC) data with brainvoyager QX: From single-subject to cortically aligned group general linear model analysis and self-organizing group independent component analysis. Human Brain Mapping, 27(5), 392-401.

Goldberg, I. I., Harel, M., \& Malach, R. (2006). When the brain loses its self: Prefrontal inactivation during sensorimotor processing. Neuron, 50(2), 329-339.

Golland, Y., Bentin, S., Gelbard, H., Benjamini, Y., Heller, R., Nir, Y., et al. (2007). Extrinsic and intrinsic systems in the posterior cortex of the human brain revealed during natural sensory stimulation. Cerebral Cortex, 17(4), 766-777.

Greicius, M. D., \& Menon, V. (2004). Default-mode activity during a passive sensory task: Uncoupled from deactivation but impacting activation. Journal of Cognitive Neuroscience, 16(9), 1484-1492.

Gusnard, D. A., \& Raichle, M. E. (2001). Searching for a baseline: Functional imaging and the resting human brain. Nature Reviews. Neuroscience, 2(10), 685-694.

Horovitz, S. G., Braun, A. R., Carr, W. S., Picchioni, D., Balkin, T. J., Fukunaga, M., et al. (2009). Decoupling of the brain's default mode network during deep sleep. Proceedings of the National Academy of Sciences of the United States of America, 106(27), 11376-11381.

Ishai, A., Ungerleider, L. G., \& Haxby, J. V. (2000). Distributed neural systems for the generation of visual images. Neuron, 28(3), 979-990.

Kihlstrom, J. F. (1997). Hypnosis, memory and amnesia. Philosophical Transactions of the Royal Society of London. Series B, Biological Sciences, 352(1362), 1727-1732.

Knauff, M., Fangmeier, T., Ruff, C. C., \& Johnson-Laird, P. N. (2003). Reasoning, models, and images: Behavioral measures and cortical activity. Journal of Cognitive Neuroscience, 15(4), 559-573.

Kupers, R., Faymonville, M. E., \& Laureys, S. (2005). The cognitive modulation of pain: Hypnosis- and placeboinduced analgesia. Progress in Brain Research, 150, 251-269.

Laureys, S. (2005). The neural correlate of (un)awareness: Lessons from the vegetative state. Trends in Cognitive Sciences, 9(12), 556-559.

Laureys, S., Goldman, S., Phillips, C., Van Bogaert, P., Aerts, J., Luxen, A., et al. (1999). Impaired effective cortical connectivity in vegetative state: Preliminary investigation using PET. NeuroImage, 9(4), 377-382.

Laureys, S., Perrin, F., \& Bredart, S. (2007). Self-consciousness in non-communicative patients. Consciousness and Cognition, 16(3), 722-741.

Lou, H. C., Luber, B., Crupain, M., Keenan, J. P., Nowak, M., Kjaer, T. W., et al. (2004). Parietal cortex and representation of the mental Self. Proceedings of the National
Academy of Sciences of the United States of America, 101 (17), 6827-6832.

Maquet, P., Faymonville, M. E., Degueldre, C., Delfiore, G., Franck, G., Luxen, A., et al. (1999). Functional neuroanatomy of hypnotic state. Biological Psychiatry, 45(3), 327-333.

Mason, M. F., Norton, M. I., Van Horn, J. D., Wegner, D. M., Grafton, S. T., \& Macrae, C. N. (2007). Wandering minds: The default network and stimulus-independent thought. Science, 315(5810), 393-395.

McGeown, W. J., Mazzoni, G., Venneri, A., \& Kirsch, I. (2009). Hypnotic induction decreases anterior default mode activity. Consciousness and Cognition, 18(4), 848-855.

McKiernan, K. A., D'Angelo, B. R., Kaufman, J. N., \& Binder, J. R. (2006). Interrupting the "stream of consciousness": An fMRI investigation. NeuroImage, 29(4), 1185-1191.

McKiernan, K. A., Kaufman, J., Kucera-Thompson, J., \& Binder, J. (2003). A parametric manipulation of factors affecting task-induced deactivation in functional neuroimaging. Journal of Cognitive Neuroscience, 15(3), 394-408.

Morin, A., \& Michaud, J. (2007). Self-awareness and the left inferior frontal gyrus: Inner speech use during self-related processing. Brain Research Bulletin, 74(6), 387-396.

Oakley, D. A., \& Halligan, P. W. (2009). Hypnotic suggestion and cognitive neuroscience. Trends in Cognitive Sciences, 13(6), 264-270.

Qin, P., Di, H., Liu, Y., Yu, S., Gong, Q., Duncan, N., et al. (2010). Anterior cingulate activity and the self in disorders of consciousness. Human Brain Mapping, 31(12), 1993-2002.

Raichle, M. E., MacLeod, A. M., Snyder, A. Z., Powers, W. J., Gusnard, D. A., \& Shulman, G. L. (2001). A default mode of brain function. Proceedings of the National Academy of Sciences of the United States of America, 98(2), 676-682.

Rainville, P., Hofbauer, R. K., Bushnell, M. C., Duncan, G. H., \& Price, D. D. (2002). Hypnosis modulates activity in brain structures involved in the regulation of consciousness. Journal of Cognitive Neuroscience, 14(6), 887-901.

Rainville, P., Hofbauer, R. K., Paus, T., Duncan, G. H., Bushnell, M. C., \& Price, D. D. (1999). Cerebral mechanisms of hypnotic induction and suggestion. Journal of Cognitive Neuroscience, 11(1), 110-125.

Rainville, P., \& Price, D. D. (2003). Hypnosis phenomenology and the neurobiology of consciousness. The International Journal of Clinical and Experimental Hypnosis, 51(2), 105-129.

Rees, G. (2007). Neural correlates of the contents of visual awareness in humans. Philosophical Transactions of the Royal Society of London. Series B, Biological Sciences, 362(1481), 877-886.

Soddu, A., Boly, M., Nir, Y., Noirhomme, Q., Vanhaudenhuyse, A., Demertzi, A., et al. (2009). Reaching across the abyss: Recent advances in functional magnetic 
resonance imaging and their potential relevance to disorders of consciousness. Progress in Brain Research, 177, 261-274.

Talairach, J., \& Tournoux, P. (1988). Co-planar stereotaxis atlas of the human brain. Stuttgart: Georges Thieme Verlag.

The Executive Committee of the American Psychological Association-Division of Psychological Hypnosis, (1994). Definition and description of hypnosis. Contemporary Hypnosis, 11, 142-162.

Tian, L., Jiang, T., Liu, Y., Yu, C., Wang, K., Zhou, Y., et al. (2007). The relationship within and between the extrinsic and intrinsic systems indicated by resting state correlational patterns of sensory cortices. NeuroImage, 36(3), 684-690.

Vanhaudenhuyse, A., Boly, M., Balteau, E., Schnakers, C., Moonen, G., Luxen, A., et al. (2009a). Pain and non-pain processing during hypnosis: A thulium-YAG event-related fMRI study. NeuroImage, 47(3), 1047-1054.

Vanhaudenhuyse, A., Noirhomme, Q., Tshibanda, L. J., Bruno, M. A., Boveroux, P., Schnakers, C., et al. (2009b). Default network connectivity reflects the level of consciousness in non-communicative brain-damaged patients. Brain, 133(Pt 1), 161-171.

Vanhaudenhuyse, A., Demertzi, A., Schabus, M., Noirhomme, Q., Bredart, S., Boly, M., et al. (2011). Two distinct neuronal networks mediate the awareness of environment and of self. Journal of Cognitive Neuroscience, 23(3), 570-578.

Vogt, B. A., \& Laureys, S. (2005). Posterior cingulate, precuneal and retrosplenial cortices: Cytology and components of the neural network correlates of consciousness. Progress in Brain Research, 150, 205-217.

Wang, K., Jiang, T., Yu, C., Tian, L., Li, J., Liu, Y., et al. (2008). Spontaneous activity associated with primary visual cortex: A resting-state FMRI study. Cerebral Cortex, 18(3), 697-704.

Weissman, D. H., Roberts, K., Visscher, K., \& Woldorff, M. G. (2006). The neural bases of momentary lapses in attention. Nature Neuroscience, 9(7), 971-978.

Ylipaavalniemi, J., \& Vigario, R. (2008). Analyzing consistency of independent components: An fMRI illustration. NeuroImage, 39(1), 169-180. 